\title{
Effect of Bird Yaw/Pitch Angles on Soft Impact Damage of a Fan Assembly
}

\author{
Junjie Li $\mathbb{D},,^{1,2}$ Yunfeng Lou $\mathbb{D},,^{3}$ Gaoyuan Yu $\mathbb{D},,^{1,2}$ Tong Li $\mathbb{D}^{1,2}$ and Xianlong Jin $\mathbb{C}^{1,2}$ \\ ${ }^{1}$ School of Mechanical Engineering, Shanghai Jiao Tong University, Shanghai 200240, China \\ ${ }^{2}$ State Key Laboratory of Mechanical System and Vibration, Shanghai Jiao Tong University, Shanghai 200240, China \\ ${ }^{3}$ Department of Structural Design, Aerospace System Engineering Shanghai, Shanghai 201108, China
}

Correspondence should be addressed to Xianlong Jin; jxlong@sjtu.edu.cn

Received 15 September 2020; Revised 4 December 2020; Accepted 24 December 2020; Published 16 January 2021

Academic Editor: Ning Wang

Copyright $(92021$ Junjie Li et al. This is an open access article distributed under the Creative Commons Attribution License, which permits unrestricted use, distribution, and reproduction in any medium, provided the original work is properly cited.

\begin{abstract}
This paper presents a numerical investigation of bird attitude angles affecting the soft-impact damage of a full fan assembly. Firstly, considering the geometry of a mallard, a real bird model is established by the Smoothed Particle Hydrodynamics (SPH) method and calibrated with available test data. Then, complying with airworthiness requirements, simulations of a full-bladed fan assembly subjected to a real bird were conducted to determine the critical ingestion parameters (CIP). Furthermore, a real bird with different attitude angles aimed at a full fan assembly was simulated. Results show that attitude angles of the bird produce a significant impact on the effect of the bird strike on rotating blades and would increase the possibility of blade failures, especially for the yaw angle of $-45^{\circ}$ and the pitch angle of $-60^{\circ}$. It is invaluable for commercial airlines and engine manufactures to provide safe flight and landing by adopting the real bird model with critical yaw and pitch angles in the design for resistance to bird ingestion.
\end{abstract}

\section{Introduction}

Bird strikes have been presenting the main threat to aircrafts since the beginning of aviation history. All available statistics indicate that the bird-strike hazard is increasing dramatically, due to the significant expansion of wild bird populations, as well as, to some extent, because of the steady increase in air transport [1]. Therefore, aviation authorities require that all forward facing components need to prove a certain level of bird-strike resistance in certification tests before they are allowed for operational use [2]. However, according to a large number of reported bird-strike incidents, substantial damage to aircraft structures occurs even though the involved energies of the bird did not achieve the aircraft certification standard. It indicates that only taking the mass and impact speed of the bird into account is far from enough.

Initially, early studies were commonly based on theoretical and experimental studies. Wilbeck $[3,4]$ conducted a comprehensive set of experimental studies on bird impacts on various structures regarding different bird sizes, initial velocities, bird substitutes, and oblique impacts. It was found that real birds behave as fluids during impact at velocities larger than $100 \mathrm{~m} / \mathrm{s}$, and the impact process consists of four typical phases. In recent times, much effort and significant progress have been done to get better insight into simulating the process of bird-strike events, involving substitute bird models [5, 6], numerical methods [7-9], and material models $[10,11]$. It can be concluded that the substitute model with bird shapes, namely, ellipsoid and hemispherical-ended cylinder (aspect ratio of 2), is recommended, associated with material properties of homogenized fluidic materials. The equation of state is used to describe the compressibility characteristics of bird material.

However, the values of Hugoniot pressure obtained from theoretical and experimental results are so far from each other, especially at lower velocities [12]. Meanwhile, the values obtained from numerical results calculated by different authors are in a wide range between the experimental and theoretical values $[2,12]$. Therefore, some scholars 
shifted the focus to the real bird model. Lakshmi [13] used a multimaterial bird model with a more realistic bird shape to capture a more detailed impact load spectrum. McCallum et al. [14] developed a physically representative bird model of a Canadian goose. The results show that, compared with the traditional model, the physically representative bird model produces a lower Hugoniot pressure and higher magnitude of peak impact force with longer duration. Hedayati et al. $[12,15]$ established a real bird model based on the mallard CT-scan image data. They found that the numerical results of the realistic bird model are closer to the available experimental results than those in the case of the traditional model.

Bird strikes are the major factor of blade damage for aircraft engines [16]. It is worth noting that, in a large number of incidents, the involved bird energy was lower than the magnitude of impact energy in certification, whereas aircraft structures can be substantially damaged [17]. In a typical field-event of the bird strike, it is common to observe a single bird coming into contact with multiple blades with respect to arbitrary attitude angle. Projectile yaw during impact would result in a variation in the impact loading history [4]. On that point, several research works have been done to capture the amount of damage imposed on blades due to bird impact, considering bird orientation or pitch/yaw angles [18-20]. The results reveal that bird orientation has a significant effect on the impact force. However, with respect to a realistic bird shape, not only is the bird attitude far more complicated, but also the effect of bird orientation on rotating blades during the bird strike is different for yaw and pitch angles. Moreover, it is difficult and complicated to record attitude angles of bird both in physical tests and in a field-event of bird strikes. The highpressure gas cannon is not capable of firing a real bird or a substitute bird with arbitrary yaw/pitch angle. Biologically inspired motion modelling and control algorithms [21-25] may seem like a good choice to determine the bird attitude, which is urgent to study. Attitude angles in our research are assumed in a wide range from $0^{\circ}$ to $60^{\circ}$.

The study presented in this paper aims to focus on attitude angels of a realistic bird affecting soft impact damage of jet engine blades. Considering the shape of a real mallard in a published literature [12], a new bird model was established using the SPH approach and validated against the latest published experimental results [26]. To determine the influence of bird orientation on the blade damage, the realistic bird model with various attitude angles targeted at a fan assembly has been developed. The simulations were performed based on Magic Cubic-II of Shanghai Supercomputer Centre, using LS-DYNA FE code.

\section{Theoretical Background}

2.1. Soft Impact Theory. Figure 1 shows the main stages and the pressure profile of a typical bird-strike process, a normal impact of a flat cylinder on a rigid plate. At the moment of impact in Figure 1, the bird material is rapidly decelerated, and a shock wave is initiated at the bird-target interface, resulting in a sharp rise in pressure. The shockwave pressure

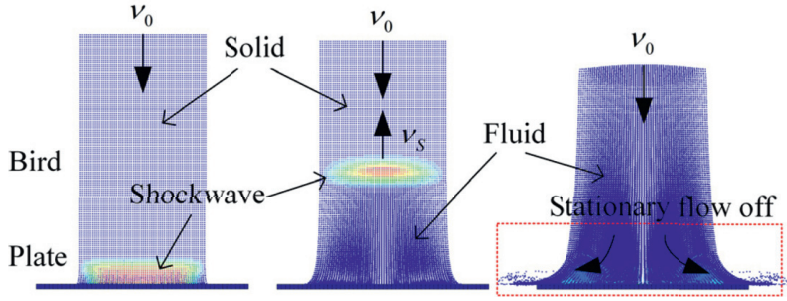

(a)

(b)

(c)

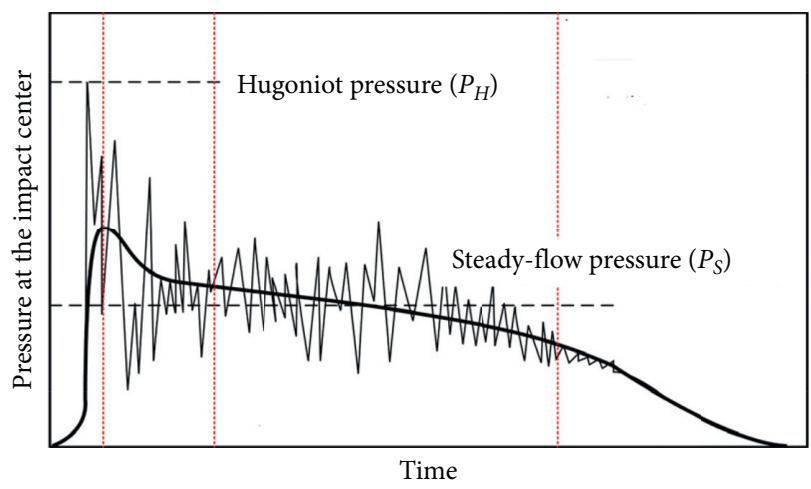

(d)

FIGURE 1: Main phases and pressure profile of a bird strike event. (a) Solid-structure impact. (b) Solid-fluid transition. (c) Fluidstructure impact. (d) Impact pressure profile.

exceeds the strength of bird material to a large extent. Consequently, as the shockwave propagates through the bird body in Figure 1, it rapidly breaks the internal bonds of birds, generating a transition from a solid towards a fluid phase. The bird material is transitioned to a fluid-like medium. The high-pressure gradient across the free surface of bird and the surrounding air forces out shocked material radially [27]. This behavior is known as shock release. With the propagation of release waves towards the center of the bird, the pressure of the bird material gradually decays to the fluid pressure. As the bird strike progresses in Figure 1, the bird material is progressively forced out of the original bird volume and spreads outwards nonlinearly. With the bird tail approaching the target, the bird-strike pressure decays to zero. Figure 1 shows the pressure at the center of the impact.

The shockwave pressure (Hugoniot pressure, $P_{H}$ ) at the initial impact (see Figure 1) is determined by [28]

$$
P_{H}=\rho_{0} \nu_{S} \nu_{0},
$$

in which

$$
v_{S}=(1-z)\left(C+S_{1} v_{0}\right)+z v_{a},
$$

where $\rho_{0}$ is the initial density of the bird. $v_{S}, v_{0}$, and $v_{a}$ represent the speed of shock wave, impact speed of the bird, and sound speed, respectively. $z$ represents bird porosity. $C$ and $S_{1}$ are coefficients of the relationship between the shock and particle velocities.

The stagnation pressure $P_{S}$ during the liquid impact (see Figure 1) is given by the following equation [28]: 


$$
P_{S}=\frac{k}{1-z} \rho_{0} v_{0}^{2},
$$

where the constant $k$ is 0.5 for an incompressible fluid [27].

2.2. Loads on Blades during Impact. In a practical fan blade application, the impact progress is far more complex. Figure 2 indicates the bird-slicing action during the impact. The bird is represented as a flat cylinder. As soon as a bird comes into contact with blades, it undergoes cut into several slices by the blade leading edge in the direction of the relative velocity $V_{\text {Relative. }}$

Blades subjected to a bird are invariably an "oblique impact" event, consisting of two phases [29]: the bird-slicing action by multiple rotating blades; each individual bird slice travelling along the blade airfoil. Thus, the impact generates both a slicing-impact load on the blade leading edge and a bird-slice turning load acting on the concave surface, which can be expressed as [29]

$$
F_{\text {Bird-slice }}=F_{\text {slicing }}+F_{\text {travel }} \text {. }
$$

At the moment of the leading edge slicing a bird projectile, it produces a high-intensity shock wave. For the initial impact area on the concave surface is almost a point, the effective load generated by the shock-wave pressure is not significant, and thus its contribution is ignored [29]. Thus, the slicing-impact load is determined by the slicing stagnation pressure [29].

$$
F_{\text {slicing }}(t)=B_{a}(t) P_{\text {stagnation }},
$$

in which the slicing stagnation pressure is determined by

$$
P_{\text {stagnation }}=\frac{1}{2} \rho_{0}\left(v_{\text {impact }}\right)^{2},
$$

where $B_{a}(t)$ denotes the bird-foot-print area on the blade leading edge. $v_{\text {impact }}$ represents the normal component of the relative velocity $V_{\text {Relative }}$ (see Figure 2 ) on the blade leading edge.

\subsection{Airworthiness Standards of Aircraft Engines.} Currently, aviation authorities require that all new commercial aero-engines must substantiate physical certification tests before operational use. These requirements are compiled in the Federal Aviation Regulations (FAR), Chinese Civil Aviation Regulations (CCAR), and the Certification Specifications (CS) of the European Aviation Safety Agency (EASA) [2]. According to airworthiness standards of FAR $\$ 33.76$ [30], for the inlet throat area $2.37 \mathrm{~m}^{2}$ of the jet engine presented in this study, it must be substantiated that the fan assembly is subjected to a medium bird of $1.15 \mathrm{~kg}$ under FAR $\$ 33.76$ (c) (3), aimed at the most critical location outboard of the primary core flow path [30]. Figure 3 indicates the location of target point on the first exposed rotating stage of the engine. The airfoil height is measured at the leading edge of the blade. The target point for bird ingestion is determined by impact loading on rotating blades, as well as the possibility of blade failures [31].

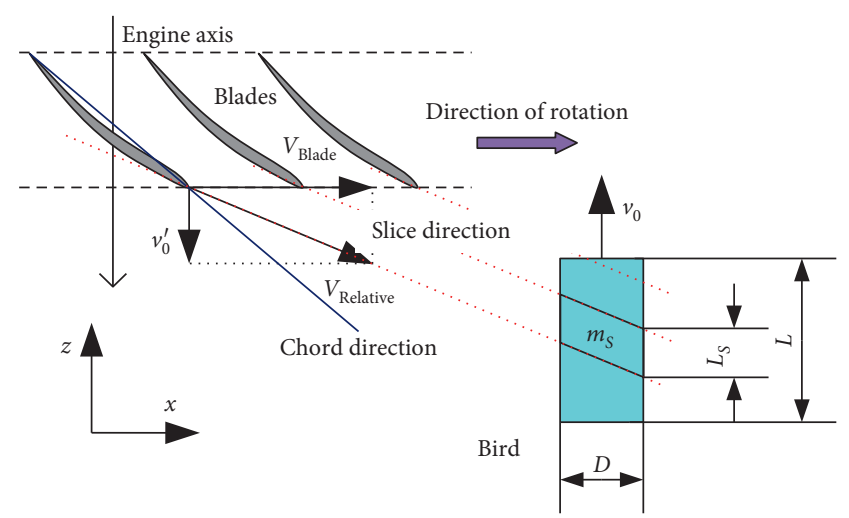

Figure 2: The bird slicing action by the blade leading edge.

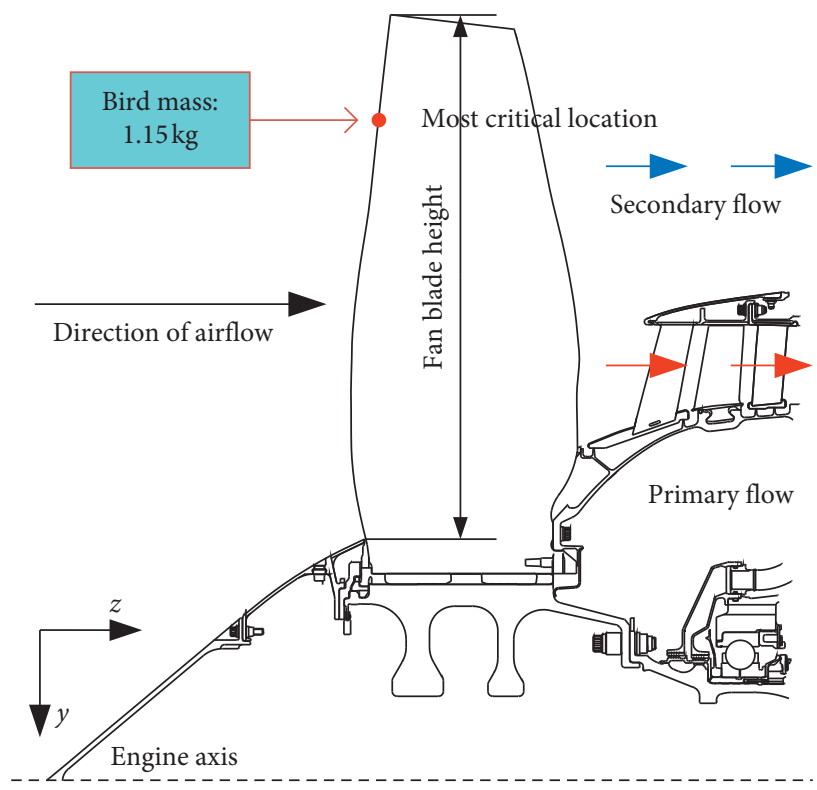

Figure 3: Location of target point on the leading edge of a fan blade.

\section{Bird Modelling}

3.1. The SPH Method. The SPH method is increasingly used in bird-strike simulations as it has already been proved to be quite capable of simulating high deforming matter with defragmentation [14]. With the SPH technique, the bird was represented as a set of discrete particles, in which the interaction between particles was achieved through a kernel function rather than a structured mesh [12]. The SPH method is recommended in the simulation of the bird-strike process, because of its high stability, low cost, and good correlation with experimental observations in terms of scattering particles [2]. Therefore, the SPH approach was adopted to model a real bird of mallard.

3.2. Geometry of a Real Bird. According to the reported bird strike incidents resulting in substantial damage to civil aircraft components in the period 1990-2017 [32], the waterfowl had been the most threatened species for civil aviation safety, 
accounting for $28 \%$ of the total specified species. Therefore, the mallard (a typical species of waterfowl) is represented as a general realistic bird model. Since a real bird consists of several internal cavities, bone structures, etc. with complex geometry, the presented bird model can reflect the bird shape to some extent, not exactly the same as the real one. The main geometric characteristics are given as follows: (1) Wilbeck [3] found that bone effect of a bird can be assumed negligible, and thus a uniform density of the real bird model is used; (2) the head is simplified to be an ellipsoid, and the neck was considered as a circular-conical-frustum [19]; (3) geometric parameters of the bird torso were modelled considering the geometry of a real mallard bird in Ref. [12]; (4) the mass of bird wings accounted for $19 \%$ of the total mass in accordance with Ref. [14]. The interparticular distance is $2 \mathrm{~mm}$, and the amount of $\mathrm{SPH}$ particles is 153,621, as shown in Figure 4.

3.3. Bird Material Constitutive Model. With a general material model for both solids and fluids to describe the fluidic behavior of the bird material, the Cauchy stress tensor is divided into a hydrostatic part and a deviatoric part [16].

$$
\sigma_{i j}=-P \delta_{i j}+s_{i j}
$$

in which the hydrostatic pressure $P$ is written as

$$
P=-\frac{\sigma_{k k}}{3}=\frac{-\left(\sigma_{11}+\sigma_{22}+\sigma_{33}\right)}{3},
$$

where $\sigma_{i j}$ represents stress tensor, and $s_{i j}$ represents deviatoric stress tensor. Variable $\delta_{i j}$ represents Kronecker delta symbol.

Since the compression of bird material during impact induces a change in the bird density [27], the Mie-Grüneisen equation of state (EOS) was used to reflect the relationship between the pressure and the density [15].

$$
\begin{aligned}
P= & \frac{\rho_{0} C^{2} \mu\left[1+\left(1-\left(\gamma_{0} / 2\right)\right) \mu-(a / 2) \mu^{2}\right]}{\left[1-\left(S_{1}-1\right) \mu-S_{2}\left(\mu^{2} / \mu+1\right)-S_{3}\left(\mu^{3} /(\mu+1)^{2}\right)\right]^{2}} \\
& +\left(\gamma_{0}+a \mu\right) E .
\end{aligned}
$$

A linear EOS is adopted for the bird material model [26], and equation (9) can be written as

$$
P=\frac{\rho_{0} C^{2} \mu}{\left[1-\left(S_{1}-1\right) \mu\right]^{2}},
$$

where $C, S_{1}, S_{2}$, and $S_{3}$ are coefficients of the relationship between the shock and particle velocities, and $\gamma_{0}$ represents Mie-Grüneisen gamma. $a$ is the first-order volume correction to $\gamma_{0} . \mu$ represents the relative change in density

Porcine gelatine with $10 \%$ porosity is used instead of the bird material [26]. Parameters of porcine gelatine can be obtained from Ref. [33]. Thus, for the developed bird model, parameters are given as follows: $\rho_{0}=954 \mathrm{~kg} / \mathrm{m}^{3}, C=1447 \mathrm{~m} / \mathrm{s}, S_{1}=1.77$.
3.4. Attitude Angle Description. In this research work, bird attitude was defined based on the Tait-Bryan angles. The Tait-Bryan angles are three angles, named as yaw angle $\alpha$, pitch angle $\beta$, and roll angle $\gamma$. They were introduced to describe the orientation of a bird. As shown in Figure 5, a right-handed Cartesian coordinate system was defined in the center of bird gravity, and any bird attitude can be parameterized by three Tait-Bryan angles $\alpha, \beta$, and $\gamma$.

In a field event of the bird strike, it is difficult and complicated to record the Tait-Bryan angles of bird ingestion. Attitude angles of the real bird are assumed in a wide range from $0^{\circ}$ to $60^{\circ}$ and the orientation of bird based on an individual Tait-Bryan angle was studied at a time. Considering the weight of wings accounting for about $19 \%$ bird mass [14], the effect of the roll angle on the slicing action of a bird is relatively small. Therefore, bird attitude based on the roll angle was neglected. Yaw angle $\alpha$ and pitch angle $\beta$ were selected as $\pm 15^{\circ}, \pm 30^{\circ}, \pm 45^{\circ}$ and $\pm 60^{\circ}$, respectively. Figure 6 shows the attitude angles of a realistic bird, where the attitude angle is represented as the angle between the roll axis and the impact velocity.

\section{Numerical Model of a Fan Assembly}

4.1. Fan Assembly Model. The fan assembly consists of 24 equally spaced $\left(15^{\circ}\right)$ wide-chord blades and a fan disc. The fan assembly was modelled with 8-noded solid elements. Bending is the basic mode of load carrying capacity for blades during impact. With a single-point integration at the element centroid, solid elements can carry membrane stresses only [34]. Thus, blades were assigned 3 layers of solid elements through the thickness. A tied-contact relationship was assumed to represent the attachment between the blade and the fan hub. Fixed boundary constraints of $\mathrm{z}$-displacement direction were defined on the side of the hub component. To restrict nonphysical deformations relevant to zero energy modes, stiffness hourglass control with exact volume integration [34] was applied to the simulation model. Figure 7 shows the finite element model of the fan assembly. The fan assembly consists of 165,200 solid elements with a total of 222,912 nodes. The minimum element size of the fan assembly model was $0.42 \mathrm{~mm}$ at the tip of the blade leading edge, and the corresponding time step for explicit dynamic simulation was $4.06 \mathrm{E}-8 \mathrm{~s}$. In addition, Figure 7 gives numbers to fan blades during slicing a bird so that it can identify the blade damage in the simulation of the impact on a fully bladed fan rotor.

4.2. Blade Material Constitutive Model. Bird strike events can be described as high strains and high strain rates in short duration with considerable intensity [35]. Therefore, the empirical Johnson-Cook relation was selected [36].

$$
\sigma_{y}=\left(A+B \varepsilon^{n}\right)\left(1+C \ln \dot{\varepsilon}^{*}\right)\left(1-T^{* m}\right),
$$

in which 


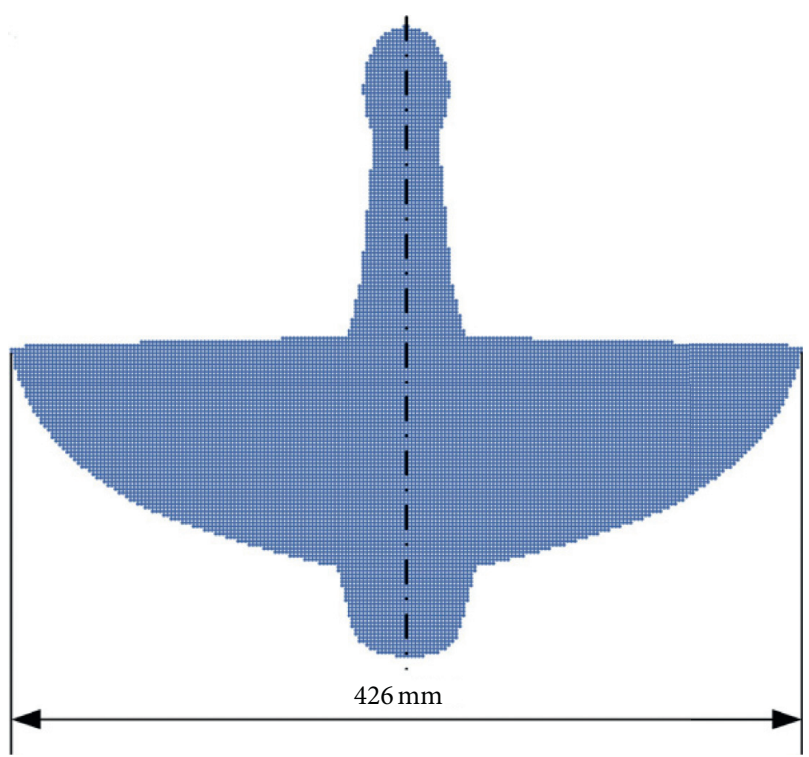

(a)

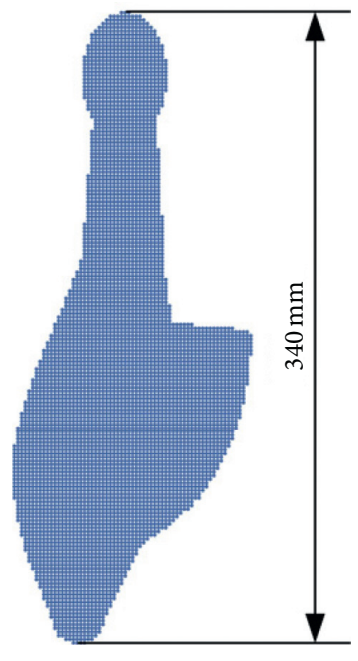

(b)

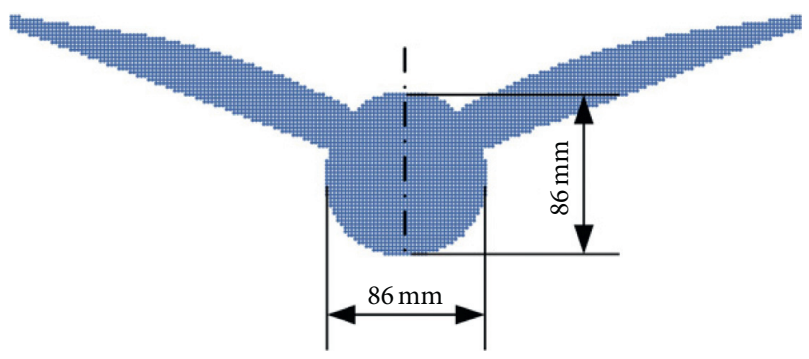

(c)
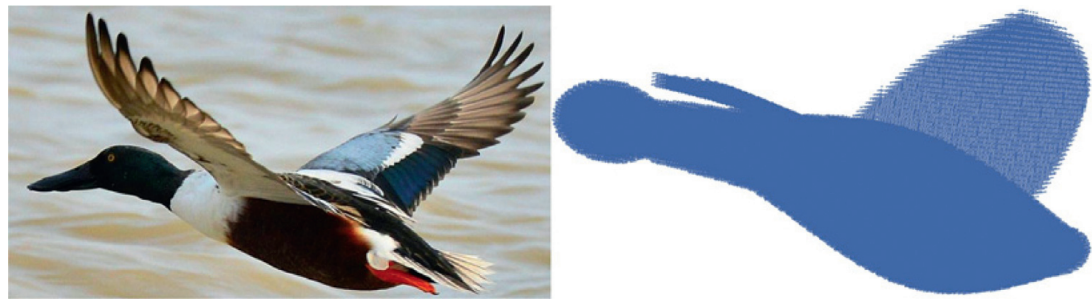

(d)

Figure 4: A realistic bird model by the SPH method. (a) Left view. (b) Front view. (c) Bottom view. (d) A real mallard compared to the SPH model.

$$
T^{*}=\left(T-T_{\text {room }}\right)\left(T_{\text {melt }}-T_{\text {room }}\right)
$$

where $\sigma_{y}$ represents the equivalent von Mises stress; $\varepsilon$ represents the equivalent plastic strain; and $\dot{\varepsilon}^{*}$ represents the normalized equivalent plastic strain rate. The parameters $A$, $B, C, m$ and $n$ are material constants. $T, T_{\text {melt }}$ and $T_{\text {room }}$ represent the metal temperature, melting temperature, and room temperature, respectively.

Material fracture is determined by a cumulative damage law, a function of mean stress, strain rate, and temperature [36].

$$
D=\sum \frac{\Delta \varepsilon}{\varepsilon_{f}}
$$

in which

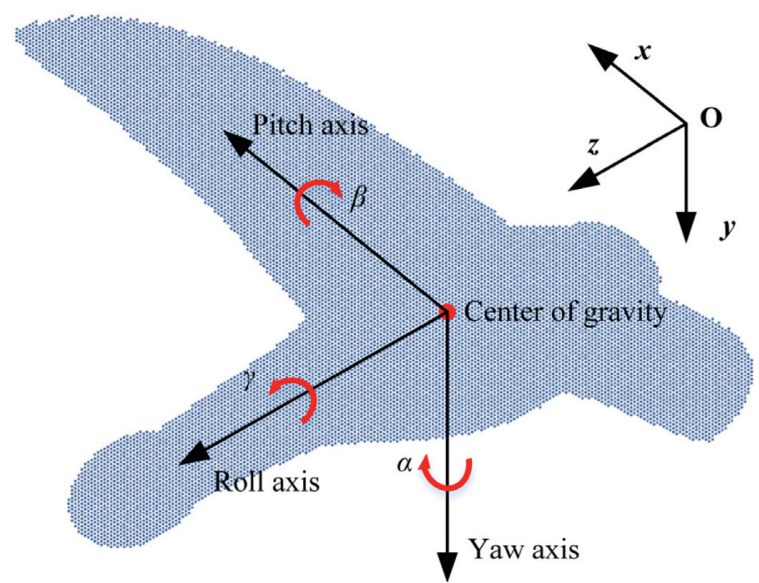

Figure 5: Definition of the Tait-Bryan angles. 

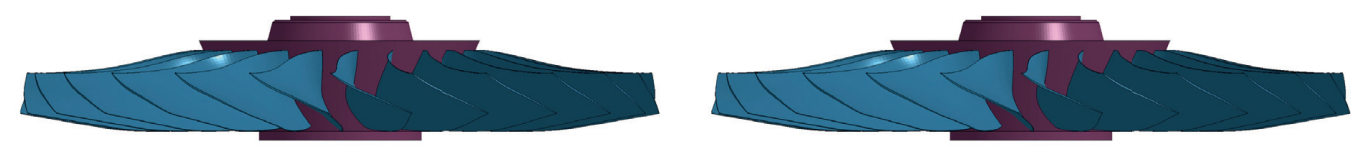
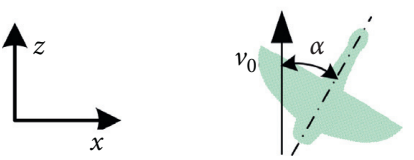

(a)

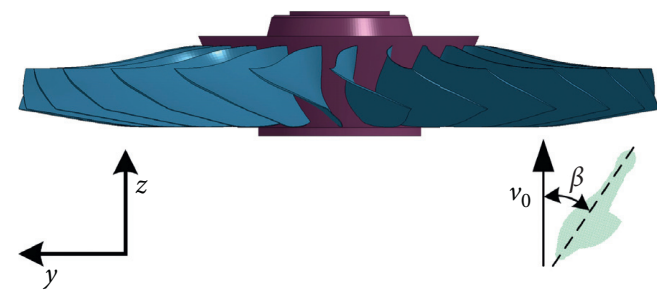

(c)

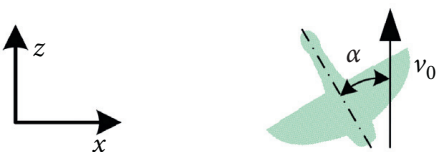

(b)

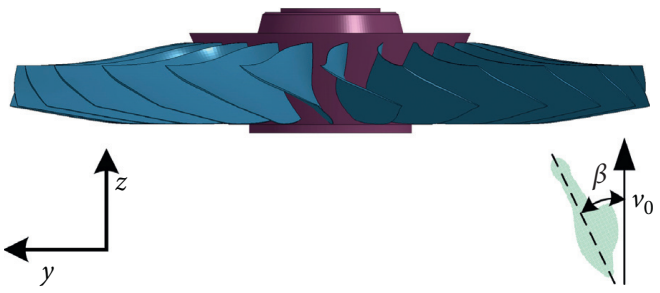

(d)

Figure 6: Schematic of yaw and pitch angles. (a) Positive yaw angle $\alpha$. (b) Negative yaw angle $\alpha$. (c) Positive pitch angle $\beta$. (d) Negative pitch angle $\beta$.

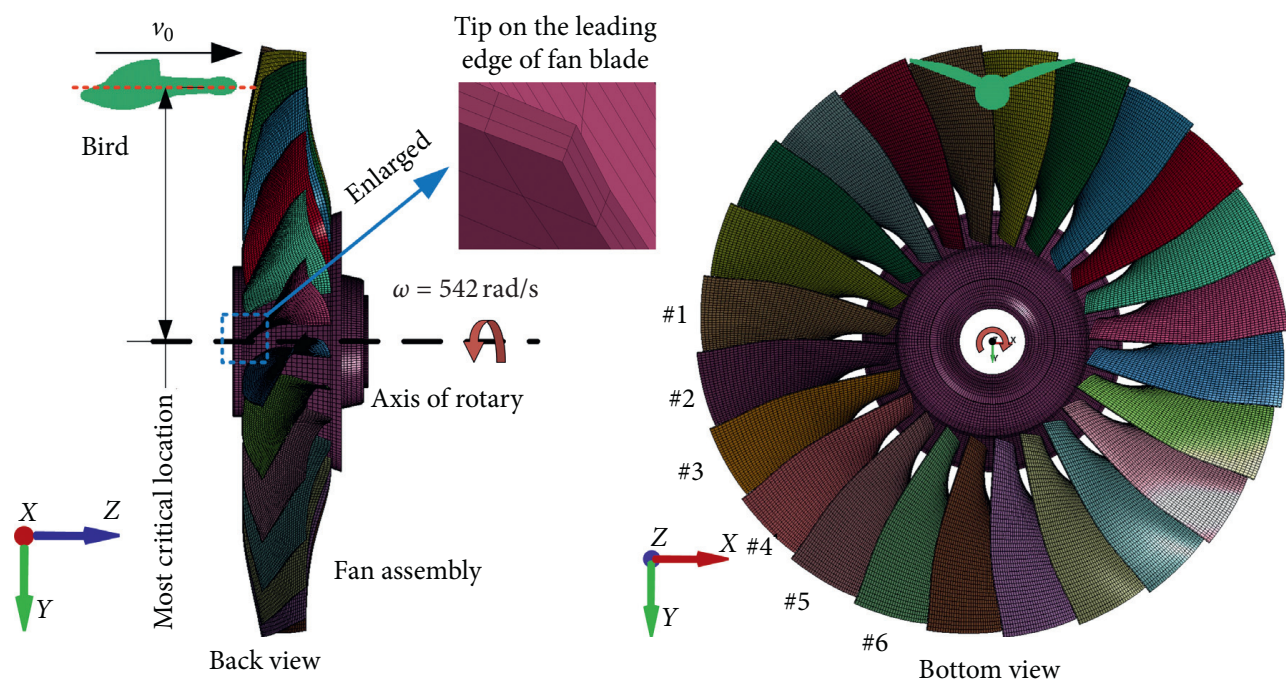

FIGURE 7: FE model of a fan assembly subjected to a bird.

$\varepsilon_{f}=\left[D_{1}+D_{2} \exp \left(D_{3} \sigma^{*}\right)\right]\left[1+D_{4} \ln \dot{\varepsilon}^{*}\right]\left[1+D_{5} T^{*}\right]$

where $\Delta \varepsilon$ is the increment of equivalent plastic strain, and $\sigma^{*}$ is the mean normalized by the equivalent stress. $D_{1}, D_{2}, D_{3}$, $D_{4}$ and $D_{5}$ are damage constants. Failures are assumed to occur when $D=1$.

The fan assembly is made of titanium alloy Ti-6Al-4V, and material parameters are derived from Ref. [37], as listed in Table 1. In addition, the Mie-Grüneisen EOS (equation (3)) was defined in conjunction with the material constitutive model, and parameters for Ti-6Al-4V are as follows: $C=5.13 \times 10^{3} \mathrm{~m} / \mathrm{s}, S_{1}=1.028, \gamma_{0}=1.23$ and $a=0.17$ [35].
4.3. Stress Initialization. The rotating fan assembly undergoes a constant centrifugal force, resulting in significant deformation and initial stresses prior to impact. It is necessary to evaluate the prestress of the rotating components, especially for blades [16]. Thus, a preload analysis procedure was conducted by assigning rotational velocity of $542 \mathrm{rad} / \mathrm{s}$ in an implicit solution. The initial stress of blades assembly is shown in Figure 8.

\section{Results and Discussion}

5.1. Bird Model Calibration. The effect of the high-intensity shock wave on the blade damage can be ignored for the 
TABLE 1: Material properties of Ti-6Al-4V.

\begin{tabular}{lccccccc}
\hline Material & $\rho\left(\mathrm{kg} / \mathrm{m}^{3}\right)$ & $A(\mathrm{MPa})$ & $B(\mathrm{MPa})$ & $C$ & $m$ & $n$ & $D_{1}, D_{2}, D_{3}, D_{4}, D_{5}$ \\
\hline Ti-6Al-4V & $4.4 \times 10^{3}$ & 1098 & 1092 & 0.014 & 1.1 & 0.93 & $-0.09,0.25,-0.5,0.14,3.87$ \\
\hline
\end{tabular}

reason that the initial bird loading area is almost like a point loading [29]. The focus of blade damage analysis needs to be on accurately capturing the steady stagnation pressure phase of impact [27]. Thus, the stagnation pressure is represented as a criterion to calibrate bird models. Numerical simulation of a normal impact on a rigid plate was established in accordance with the experimental setup in Ref. [26]. A segment sensor was assigned at the center of the plate to extract the impact pressure. The stagnation pressures were estimated by averaging the pressure between $T_{0} / 3$ and $2 T_{0} / 3$ [26], where $T_{0}$ denotes the duration of the bird strike event. The theoretical curve of the stagnation pressure was determined by equation (3), and test data was derived from Ref. [26], as shown in Figure 9. The numerical results were in a range between theoretical and experimental values. The stagnation pressures captured by simulation of the real bird were in closer agreement with the test data than those in the case of the hemispherical-ended cylinder.

5.2. Most Critical Ingestion Parameters. The critical ingestion parameters are required to be identified for the specified bird ingestion [30]. In this section, simulations of a full fan assembly subjected to a real bird were performed to determine the critical location and ingestion speed under FAR $\$ 33.76(\mathrm{c})$ (1) and FAR $\$ 33.76(\mathrm{c})(3)$.

5.2.1. Most Critical Ingestion Speed. Complying with FAR $\$ 33.76(c)(1)$, the critical ingestion speed is required to reflect the most severe situation within the range of speeds used for normal flight operations up to $460 \mathrm{~m}$ (1,500 feet), but not less than V1 minimum for airplanes [30]. Therefore, simulations of the bird ingested at different speeds were performed, aimed at the fan blade height of $80 \%$. Figure 10 (a) shows the effect of ingestion speed on impact loading history. The peak values of impact force generated by a real bird targeted at speeds of $60 \mathrm{~m} / \mathrm{s}, 65 \mathrm{~m} / \mathrm{s}, 70 \mathrm{~m} / \mathrm{s}, 80 \mathrm{~m} / \mathrm{s}, 105 \mathrm{~m} / \mathrm{s}$, and $130 \mathrm{~m} /$ $\mathrm{s}$ are $183.35 \mathrm{KN}$ at $3.95 \mathrm{~ms}, 182.53 \mathrm{KN}$ at $3.97 \mathrm{~ms}, 198.91 \mathrm{KN}$ at $3.48 \mathrm{~ms}, 210.96 \mathrm{KN}$ at $3.48 \mathrm{~ms}, 212.16 \mathrm{KN}$ at $2.99 \mathrm{~ms}$, and $170.95 \mathrm{KN}$ at $2.50 \mathrm{~ms}$, respectively. As the speed increases, the impact duration becomes shorter. It is also found that the higher the impact speed is, the earlier the peak force occurs. As the normalized sum of effective plastic strains shown in Figure 10(b), the ingestion speed of $65 \mathrm{~m} / \mathrm{s}$ caused the most severe plastic strain. Therefore, $65 \mathrm{~m} / \mathrm{s}$ was represented as the most critical speed.

5.2.2. Most Critical Exposed Location. To find out the most critical location under FAR $\$ 33.76$ (c)(1), the real bird aimed at different target points on the leading edge of blades was evaluated at a speed of $65 \mathrm{~m} / \mathrm{s}$. Figure 11(a) shows the effect of target location on the time histories of impact force. The peak values of impact force generated by a real bird aimed at

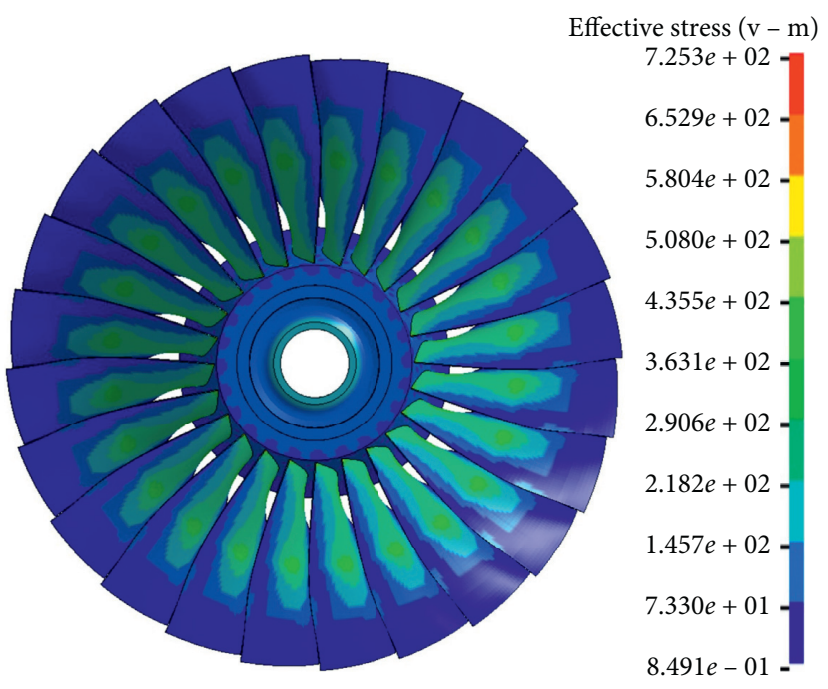

Figure 8: von Mises stress (MPa) of the fan assembly.

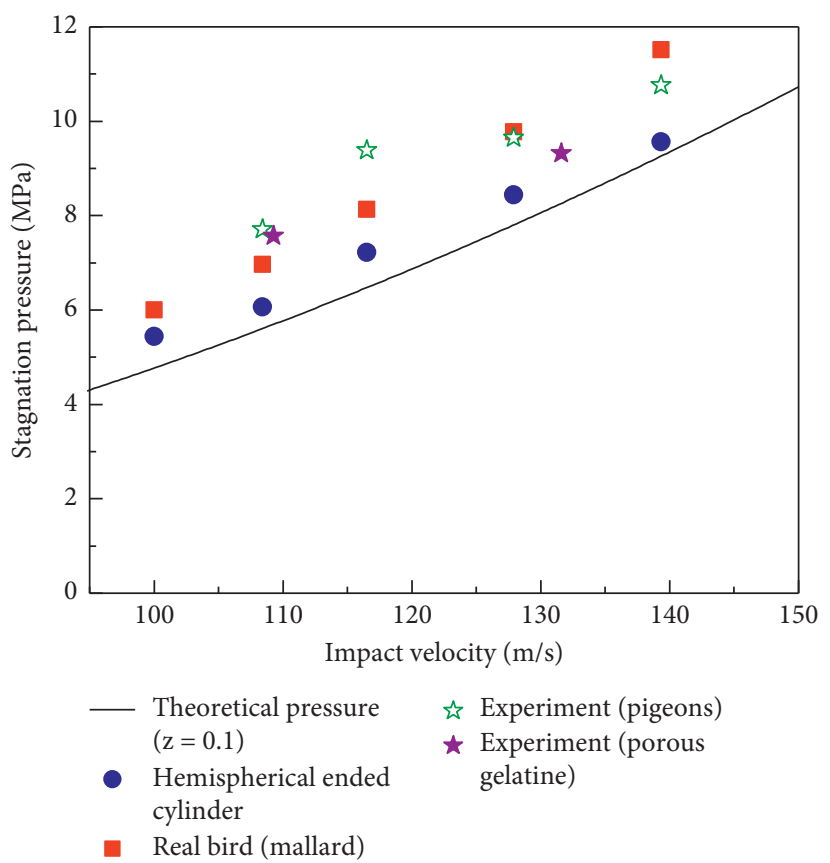

Figure 9: Calibration of stagnation pressures.

the fan blade height of $50 \%, 70 \%, 75 \%, 80 \%, 85 \%$, and $90 \%$ are $163.79 \mathrm{KN}$ at $3.84 \mathrm{~ms}, 168.25 \mathrm{KN}$ at $4.30 \mathrm{~ms}, 177.30 \mathrm{KN}$ at $3.92 \mathrm{~ms}, 182.53 \mathrm{KN}$ at $3.97 \mathrm{~ms}, 155.92 \mathrm{KN}$ at $4.39 \mathrm{~ms}$, and $171.69 \mathrm{KN}$ at $4.85 \mathrm{~ms}$, respectively. It can be observed that the impact location of $80 \%$ blade height reaches the maximum value of peak impact force. As the blade damage indicated in Figure 11(b), with the single medium bird targeted at the fan blade height of $80 \%$, it occurs to the most 


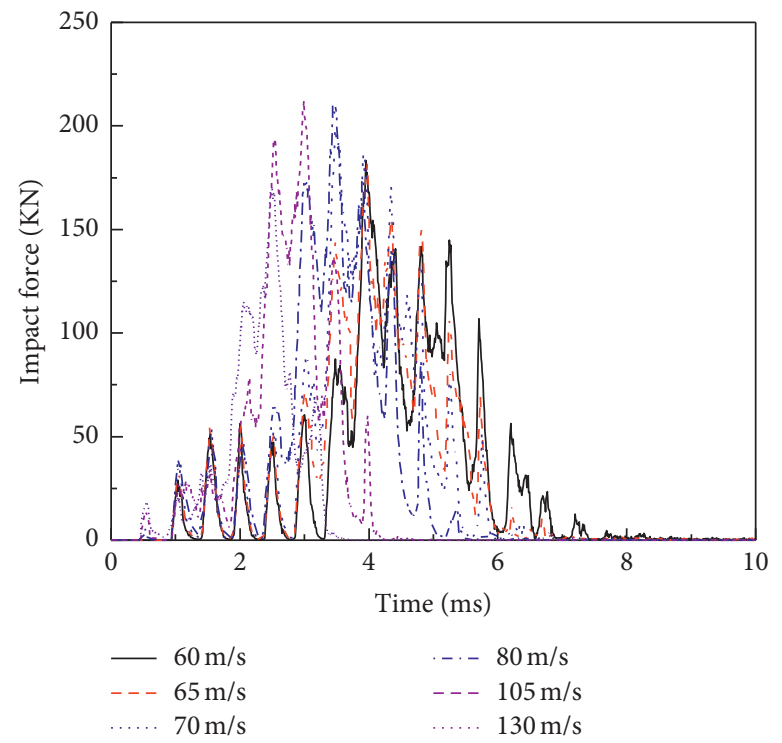

(a)

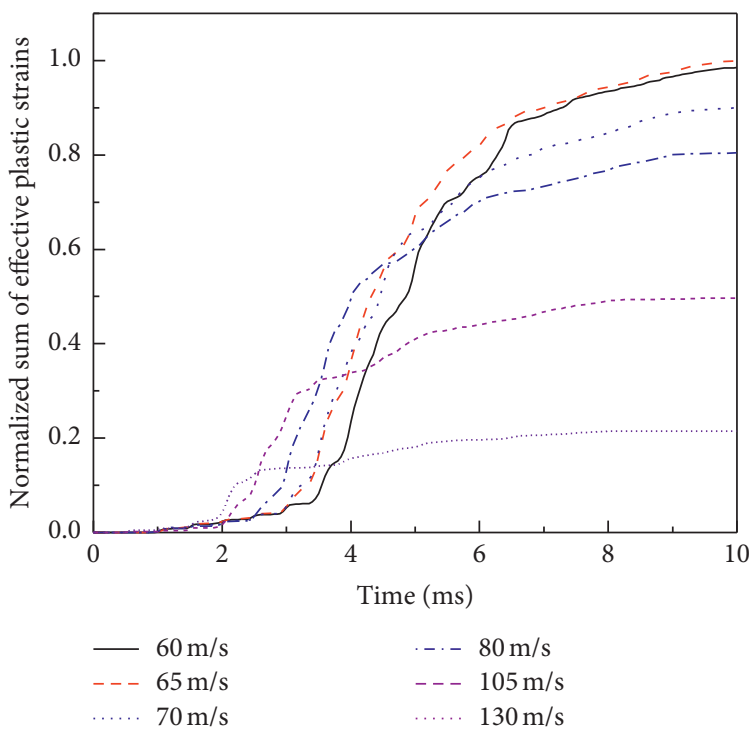

(b)

FIGURE 10: Effect of ingestion speed on the impact loading history and blade damage. (a) The impact loading history. (b) Normalized sum of effective plastic strains.

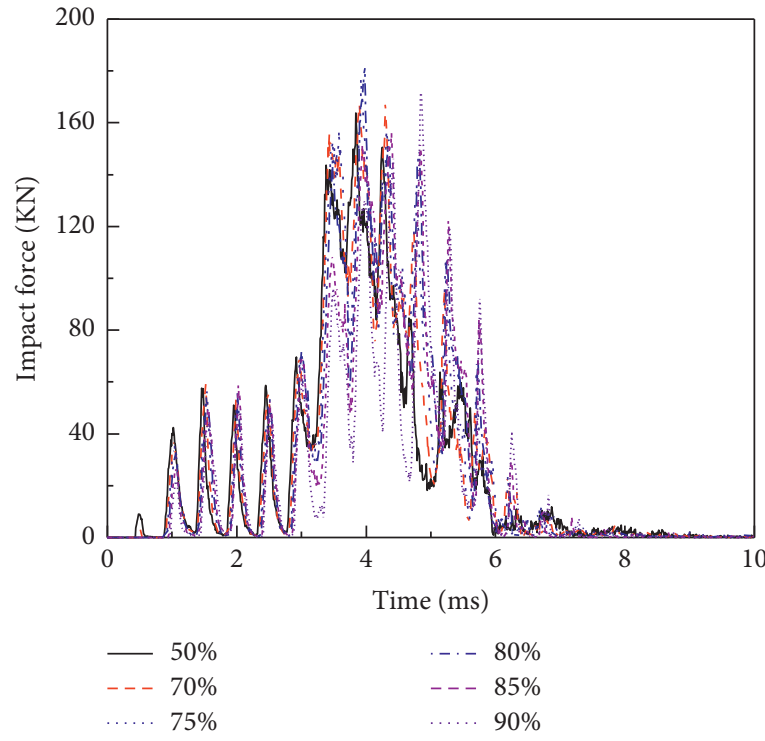

(a)

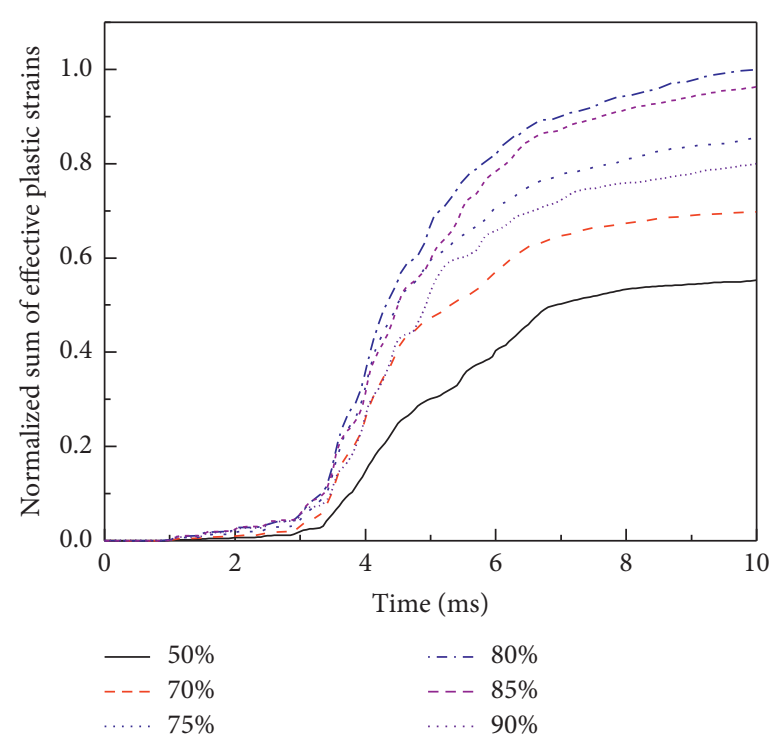

(b)

FIGURE 11: Effect of target location on the impact loading history and blade damage. (a) The impact loading history. (b) Normalized sum of effective plastic strains.

severe blade plastic strain. As a result, the most critical location for a middle-sized bird should be aimed at $80 \%$ of the fan blade height.

5.3. Effect of Attitude Angles on Soft-Impact Damage. Figure 12 shows the deformation of bird oriented along the engine axis. As expected, it can be clearly observed that, prior to the impact of the bird torso, the real bird was sliced into more pieces. The orientation of bird has a direct effect on slicing action of fan blades. With respect to different attitudes, the contact area and duration of bird strikes change, resulting in a significant impact on the effect of the bird strike on rotatory blades and the possibility of blade failures.

Figure 13 shows the effect of the yaw angle on impact loading history. As shown in Figure 13(a), peak values of impact force generated by a real bird with respect to yaw angle of $15^{\circ}, 30^{\circ}, 45^{\circ}$ and $60^{\circ}$ are $201.53 \mathrm{KN}$ at $3.97 \mathrm{~ms}$, $170.52 \mathrm{KN}$ at $4.31 \mathrm{~ms}, 176.34 \mathrm{KN}$ at $4.33 \mathrm{~ms}$, and $186.97 \mathrm{KN}$ at $4.28 \mathrm{~ms}$, respectively. As shown in Figure 13(b), the peak 

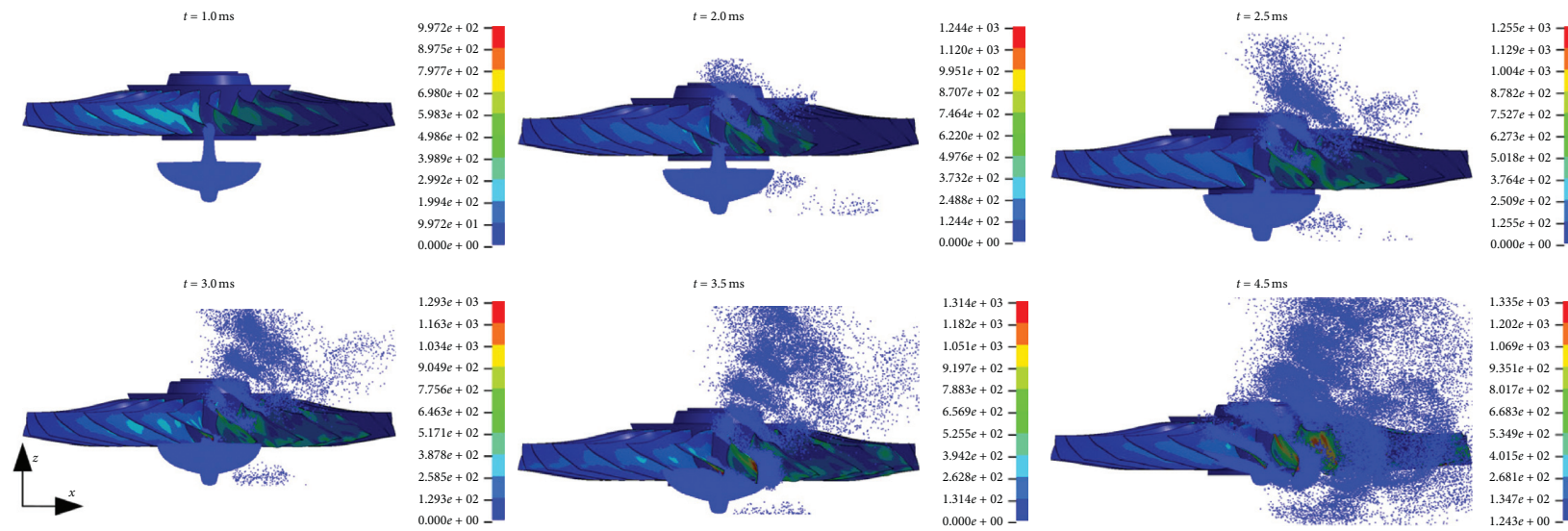

(a)

Figure 12: Bird deformation during the slicing action.

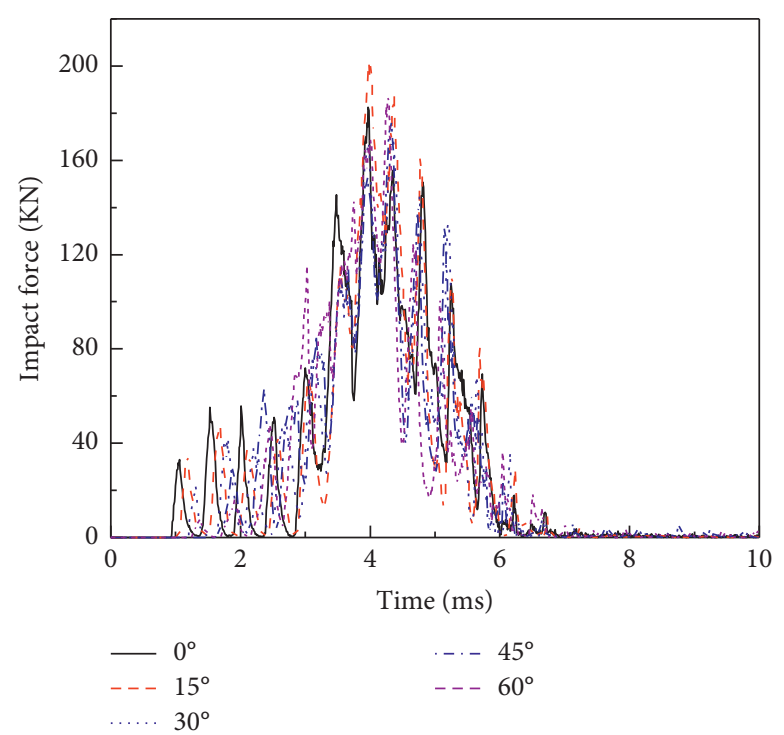

(a)

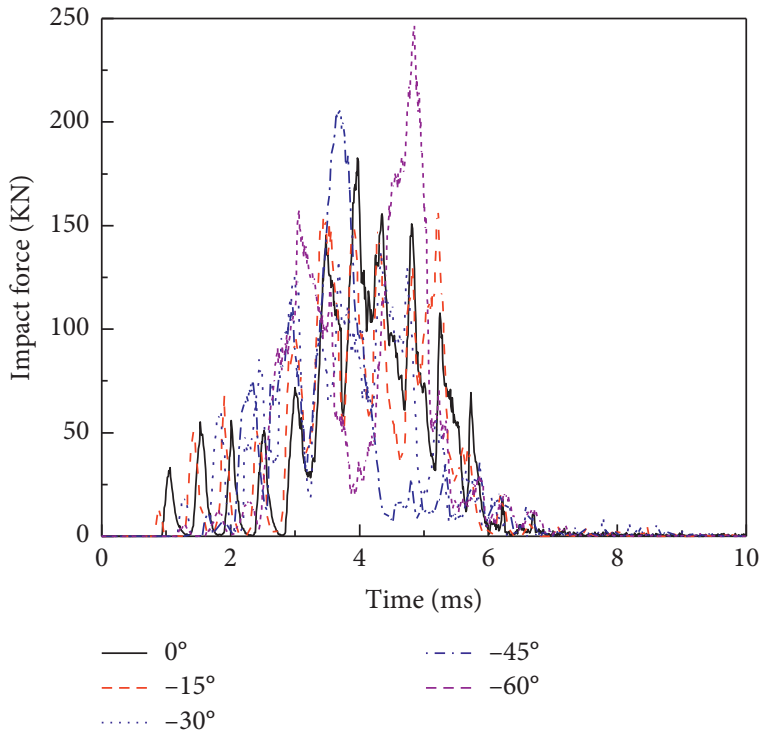

(b)

FIgURE 13: Yaw angle effect on impact loading history. (a) Positive yaw angle $\alpha$. (b) Negative yaw angle $\alpha$.

values of impact force derived from a real bird with yaw angle of $-15^{\circ},-30^{\circ},-45^{\circ}$ and $-60^{\circ}$ are $157.32 \mathrm{KN}$ at $5.22 \mathrm{~ms}$, $137.99 \mathrm{KN}$ at $4.33 \mathrm{~ms}, 206.47 \mathrm{KN}$ at $3.70 \mathrm{~ms}$, and $246.66 \mathrm{KN}$ at $4.85 \mathrm{~ms}$, respectively. It can be concluded that a yaw angle of the bird would generate a variation in the impact loading history, and a negative yaw angle has a more significant effect on the impact loading history.

Figure 14 shows the effect of pitch angle on the time histories of impact loads. As shown in Figure 14(a), with respect to pitch angles of $15^{\circ}, 30^{\circ}, 45^{\circ}$, and $60^{\circ}$, the peak impact loads are $205.15 \mathrm{KN}$ at $4.35 \mathrm{~ms}, 227.20 \mathrm{KN}$ at $3.91 \mathrm{~ms}$, $261.47 \mathrm{KN}$ at $4.33 \mathrm{~ms}$, and $269.40 \mathrm{KN}$ at $3.92 \mathrm{~ms}$, respectively. Obviously, the peak impact force increases as the positive pitch angle increases. As shown in Figure 14(b), peak values of impact loading obtained from a real bird model with pitch angles of $-15^{\circ},-30^{\circ},-45^{\circ}$ and $-60^{\circ}$ are $160.73 \mathrm{KN}$ at $3.93 \mathrm{~ms}$,
$168.28 \mathrm{KN}$ at $3.90 \mathrm{~ms}, 184.85 \mathrm{KN}$ at $3.86 \mathrm{~ms}$, and $224.06 \mathrm{KN}$ at $3.85 \mathrm{~ms}$, respectively. It is observed that a negative yaw angle would result in a variation in the impact loading history.

Figure 15 shows effective plastic strains of a single blade, which undergoes the most severe plastic deformation during impact. Obviously, with the change of the bird attitude angle, the blade undergoes more severe plastic deformation. Especially, as subjected to a real bird with a yaw angle of $-45^{\circ}$ or a pitch angle of $-60^{\circ}$, the blade suffers more than twice the magnitude of effective plastic strain compared with a real bird oriented along the engine centerline. It can be concluded that attitude angles would increase the possibility of fan blade failure. Moreover, the yaw angle of bird ingestion has a significant effect on the location of the blade with the most severe plastic deformation. 


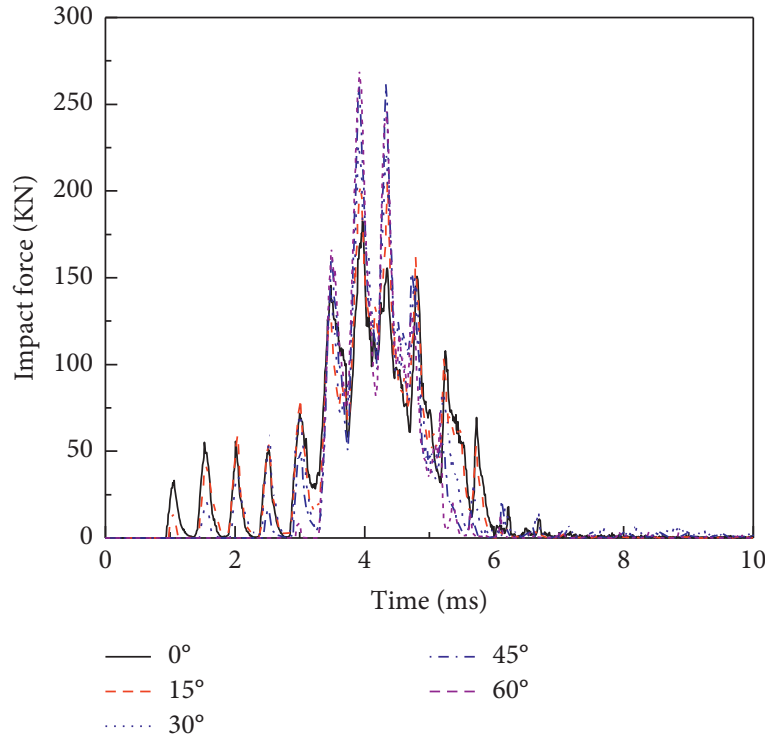

(a)

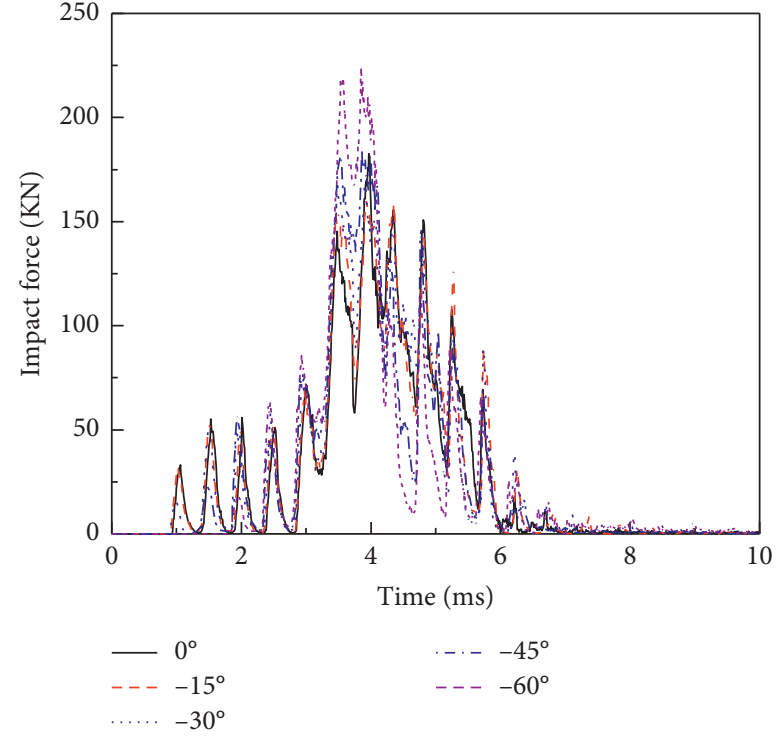

(b)

Figure 14: Pitch angle effect on impact loading history. (a) Positive pitch angle $\beta$. (b) Negative pitch angle $\beta$.
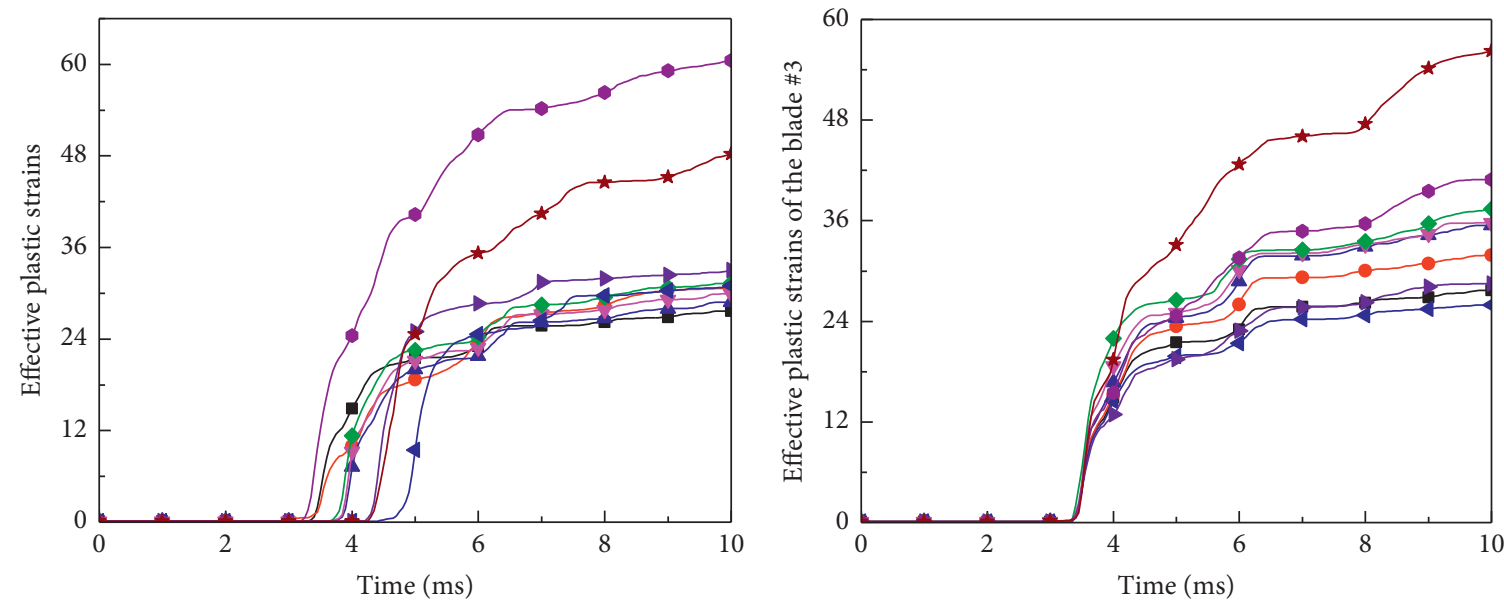

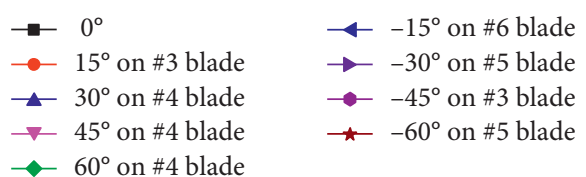

(a)

$$
\begin{aligned}
& \rightarrow 0^{\circ} \\
& -15^{\circ} \\
& \leftarrow 30^{\circ} \\
& \rightarrow \quad 45^{\circ} \\
& -60^{\circ}
\end{aligned}
$$

(b)

Figure 15: Attitude angle effect on blade damage. (a) Yaw angle $\alpha$. (b) Pitch angle $\beta$. 


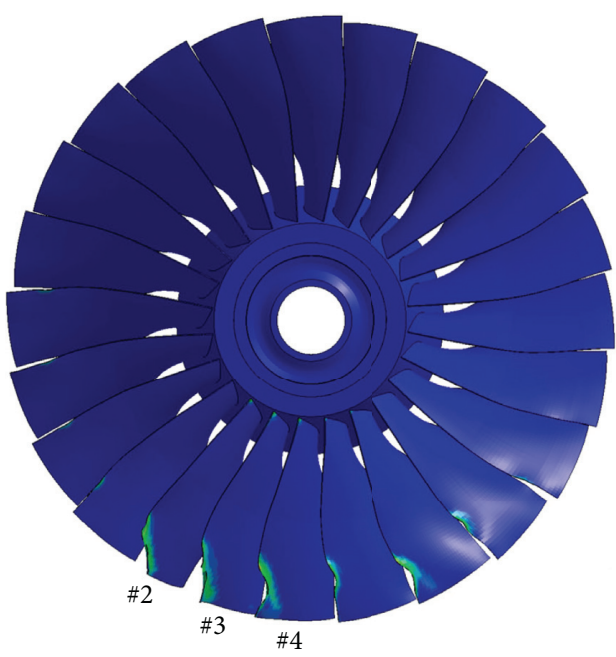

(a)
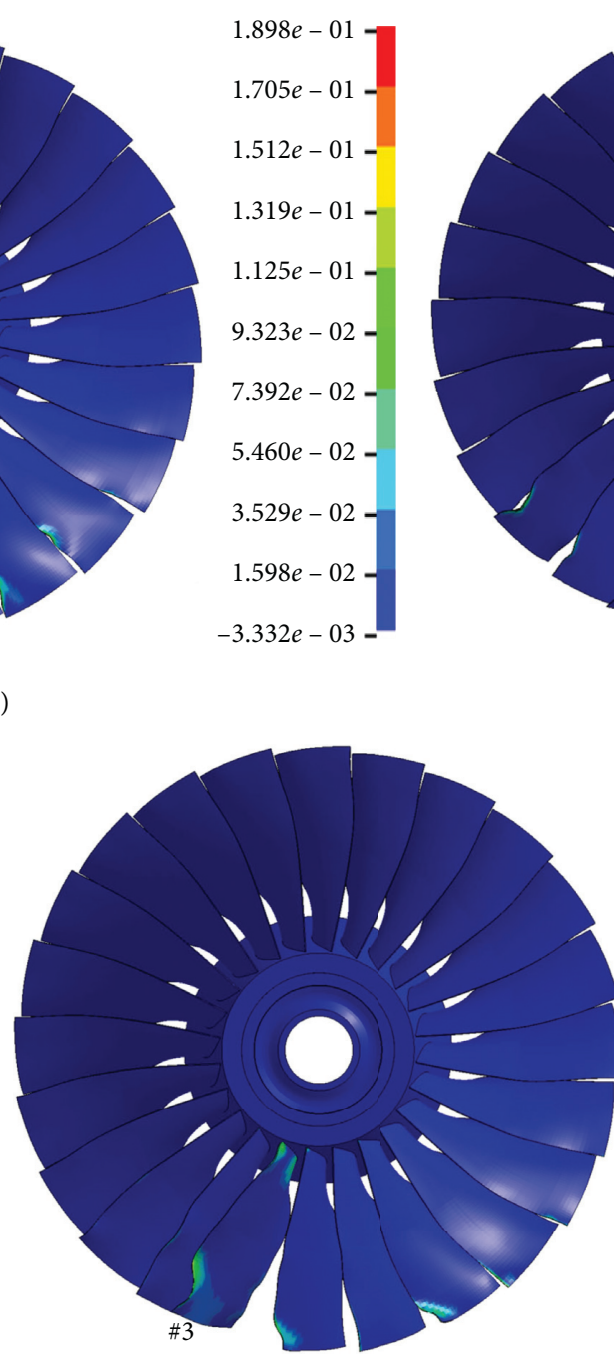

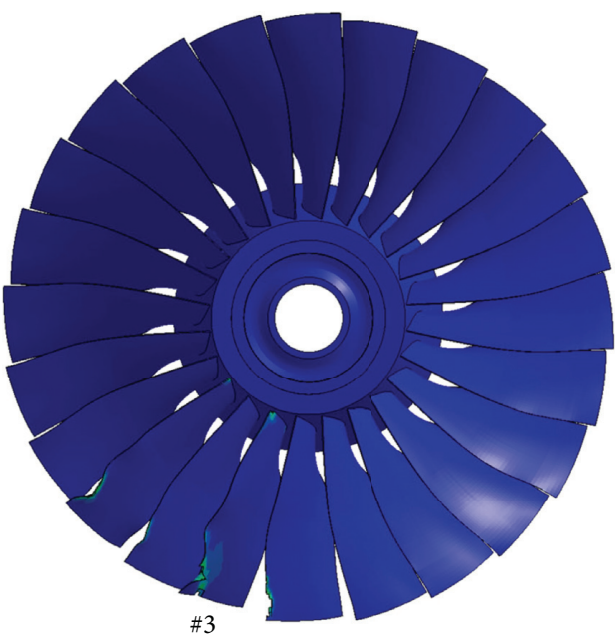

(b)

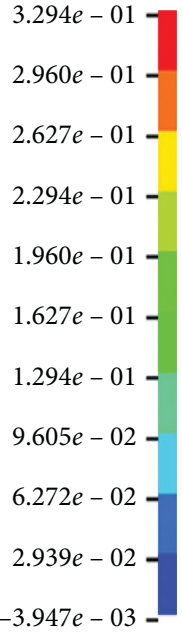

$-3.947 e-03=$

(c)

Figure 16: Effective plastic strain contours at time $t=10 \mathrm{~ms}$. (a) $0^{\circ}$. (b) $\alpha=-45^{\circ}$. (c) $\beta=-60^{\circ}$.

Figure 16 shows the effective plastic strains of the fan assembly. It can be seen that a "cusp" plastic deformation occurs at the leading edge, and the maximum plastic strain occurred to the impact location. Compared with the plastic deformation of a fan assembly during a normal impact (see Figure 16(a)), subjected to a bird with an attitude angle of $\alpha=-45^{\circ}$ and $\beta=-60^{\circ}$, fan blade failure occurs at the impact location, and the plastic deformation at the root of the fan blade leading edge is more significant, which would increase the risk of a fan blade release event.

\section{Conclusions}

Considering a geometric shape similar to what has already been published as a real mallard [12], a real bird model was developed. Then, this paper discusses the effect of attitude angles of the realistic bird model on the soft impact damage of a full fan assembly. Besides, the stagnation pressure is represented as a criterion to calibrate the developed bird model. Results show a good correlation with available test data [26].

In accordance with certification requirements, the most critical ingestion parameters for the new bird model were investigated. It is found that the real bird aimed at the fan blade height of $80 \%$ with an ingestion speed of $65 \mathrm{~m} / \mathrm{s}$ produces the most severe damage to the full fan assembly.

Complying with the critical ingestion parameters of the bird, simulations of a full fan assembly subjected to a real bird with respect to various attitude angles reveal that both yaw and pitch angles of the bird have a significant effect on the impact loading history. The blade that undergoes the highest magnitude of effective plastic strain would be confronted with a more plastic deformation than that in the case of a normal impact (attitude angle $0^{\circ}$ ), even though the impact loading decreases. Especially, as subjected to a real bird with yaw angle of $-45^{\circ}$ or pitch angle of $-60^{\circ}$, the blade suffers more than twice the magnitude of effective plastic strain compared with that of attitude angle $0^{\circ}$, and the plastic 
deformation at the root of the leading edge is more significant, which would increase the risk of a fan blade release event.

Moreover, it is invaluable to ensure the safety of commercial airlines and engine manufacture by adopting the realistic bird model with the dangerous attitude angle in the certification of engine designs for resistance to bird strikes, which will provide sufficient resistance in actual bird-strike events. However, attitude angles of the bird were set up based on the assumption in this paper. If the bird attitude could be determined through experiments or control algorithms [38-42], it is of great significance to investigate the effect of bird attitude on soft impact damage, as well as the distribution of flocking bird.

\section{Data Availability}

All data included in this study are available from the corresponding author upon request.

\section{Conflicts of Interest}

The authors declare that there are no conflicts of interest regarding the publication of this paper.

\section{Acknowledgments}

This research was supported by the National Key Research and Development Program of China (Grant no. 2016YFB0201800) and the National Natural Science Foundation of China (Grant no. 11772192).

\section{References}

[1] R. H. Mao, S. A. Meguid, and T. Y. Ng, "Transient three dimensional finite element analysis of a bird striking a fan blade," International Journal of Mechanics and Materials in Design, vol. 4, no. 1, pp. 79-96, 2008.

[2] S. Heimbs, "Computational methods for bird strike simulations: a review," Computers \& Structures, vol. 89, no. 23-24, pp. 2093-2112, 2011.

[3] J. S. Wilbeck, Impact Behavior of Low Strength Projectiles, Air Force Materials Lab, Ohio, AFFDL-TR-75-5, 1978.

[4] J. S. Wilbeck and J. L. Rand, "The development of a substitute bird model," Journal of Engineering for Power, vol. 103, no. 4, pp. 725-730, 1981.

[5] A. Airoldi and B. Cacchione, "Modelling of impact forces and pressures in Lagrangian bird strike analyses," International Journal of Impact Engineering, vol. 32, no. 10, pp. 1651-1677, 2006.

[6] M. A. Lavoie, A. Gakwaya, M. N. Ensan, D. G. Zimcik, and D. Nandlall, "“'Bird's substitute test results and evaluation of available numerical methods," International Journal of Impact Engineering, vol. 36, no. 10-11, pp. 1276-1287, 2009.

[7] M. Guida, F. Marulo, M. Meo, and M. Riccio, "Evaluation and validation of multi-physics FE methods to simulate bird strike on a wing leading edge," in Proceedings of the 13th European Conference on Composite Materials (ECCM), Stockholm, Sweden, June 2008.

[8] M. A. Lavoie, A. Gakwaya, M. N. Ensan, and D. G. Zimcik, "Review of existing numerical methods and validation procedure available for bird strike modelling," International
Journal of Applied Mathematics and Computer Science, vol. 2, no. 4, pp. 111-118, 2007.

[9] M. A. Lavoie, A. Gakwaya, M. Nejad Ensan, and D. G. Zimcik, "Validation of available approaches for numerical bird strike modeling tools," International Review of Mechanical Engineering, vol. 1, no. 4, pp. 380-389, 2007.

[10] M. A. McCarthy, J. R. Xiao, C. T. McCarthy et al., "Modelling of bird strike on an aircraft wing leading edge made from fibre metal laminates-part 2: modelling of impact with SPH bird model," Applied Composite Materials, vol. 11, no. 5, pp. 317-340, 2004.

[11] L. Nizampatnam and W. Horn, "Investigation of equation of state models for predicting bird impact loads," in Proceedings of the 46th AIAA Aerospace Sciences Meeting and Exhibit, pp. 7-10, 2013.

[12] R. Hedayati, M. Sadighi, and M. Mohammadi-Aghdam, "On the difference of pressure readings from the numerical, experimental and theoretical results in different bird strike studies," Aerospace Science and Technology, vol. 32, no. 1, pp. 260-266, 2014.

[13] L. S. Nizampatnam, Models and Methods for Bird Strike Load Predictions, Wichita State University, Wichita, Kansas, 2007.

[14] S. McCallum, H. Shoji, and H. Akiyama, "Development of an advanced multi-material bird-strike model using the smoothed particle Hydrodynamics method," International Journal of Crashworthiness, vol. 18, no. 6, pp. 579-597, 2013.

[15] R. Hedayati and S. Ziaei-Rad, "A new bird model and the effect of bird geometry in impacts from various orientations," Aerospace Science and Technology, vol. 28, no. 1, pp. 9-20, 2013.

[16] A. Serge, "Soft impacts on aerospace structures," Progress in Aerospace Sciences, vol. 81, pp. 1-17, 2016.

[17] J. Kou, F. Xu, S. Ji, and X. Zhang, "Influence of bird yaw/pitch orientation on bird-strike resistance of aircraft structures," Explosion and Shock Waves, vol. 37, no. 5, pp. 937-944, 2017.

[18] Z. Zhang, L. Li, and D. Zhang, "Effect of arbitrary yaw/pitch angle in bird strike numerical simulation using SPH method," Aerospace Science and Technology, vol. 81, pp. 284-293, 2018.

[19] D. Zhang and Q. Fei, "Effect of bird geometry and impact orientation in bird striking on a rotary jet-engine fan analysis using SPH method," Aerospace Science and Technology, vol. 54, pp. 320-329, 2016.

[20] R. H. Mao, S. A. Meguid, and T. Y. Ng, "Effects of incidence angle in bird strike on integrity of aero-engine fan blade," International Journal of Crashworthiness, vol. 14, no. 4, pp. 295-308, 2009.

[21] C. Yang, C. Chen, N. Wang et al., "Biologically inspired motion modeling and neural control for robot learning from demonstrations," IEEE Transactions on Cognitive and Developmental Systems, vol. 11, no. 2, pp. 281-291, 2019.

[22] C. Yang, C. Chen, W. He, R. Cui, and Z. Li, "Robot learning system based on adaptive neural control and dynamic movement primitives," IEEE Transactions on Neural Networks and Learning Systems, vol. 30, no. 3, pp. 777-787, 2019.

[23] C. Yang, D. Huang, W. He, and L. Cheng, "Neural control of robot manipulators with trajectory tracking constraints and input saturation," IEEE Transactions on Neural Networks and Learning Systems, pp. 1-12, 2020.

[24] H. Huang, T. Zhang, C. Yang, and C. L. P. Chen, "Motor learning and generalization using broad learning adaptive neural control," IEEE Transactions on Industrial Electronics, vol. 67, no. 10, pp. 8608-8617, 2020. 
[25] H. Huang, C. Yang, and C. L. P. Chen, "Optimal robot-environment interaction under broad fuzzy neural adaptive control," IEEE Transactions on Cybernetics, pp. 1-12, 2020.

[26] F. Allaeys, G. Luyckx, W. Van Paepegem, and J. Degrieck, "Numerical and experimental investigation of the shock and steady state pressures in the bird material during bird strike," International Journal of Impact Engineering, vol. 107, pp. 12-22, 2017.

[27] M. Kim, A. Zammit, A. Siddens, and J. Bayandor, "An extensive crashworthiness methodology for advanced propulsion systems, part I: soft impact damage assessment of composite fan stage assemblies," in Proceedings of the 49th AIAA Aerospace Sciences Meeting Including the New Horizons Forum and Aerospace Exposition, Orlando, Florida, January 2011.

[28] R. Hedayati and M. Sadighi, Bird Strike: An Experimental, Theoretical and Numerical Investigation, Woodhead Publishing in Mechanical Engineering, Elsevier, Amsterdam, Netherlands, 978-0-08-100093-9, 2016.

[29] S. K. Sinha, K. E. Turner, and N. Jain, "Dynamic loading on turbofan blades due to bird-strike," Journal of Engineering for Gas Turbines and Power, vol. 133, no. 12, Article ID 122504, 2011.

[30] Federal Aviation Administration, "Electronic code of federal Regulations," Title 14: Aeronautics and Space, National Archives and Records Administration, Washington, DC, USA, Chapter I, Subchapter C, Part 33-Airworthiness Standards: Aircraft Engines, Section 33.76, 2020.

[31] Federal Aviation Administration, "Bird ingestion certification standards," Advisory Circular, Federal Aviation Administration, Wasington, DC, USA, 33.76-1A, 2009.

[32] R. A. Dolbeer, S. E. Wright, J. R. Weller, and M. J. Begier, Wildife Strikes to Civil Aircraft in the United States 1990-2017, National Wildlife Strike Database, Washington, DC, USA, 2018.

[33] C. J. Shepherd, G. J. Appleby-Thomas, P. J. Hazell, and D. F. Allsop, "The dynamic behaviour of ballistic gelatin," AIP Conference Proceedings, vol. 1195, pp. 1399-1402, 2009.

[34] J. O. Hallquist, LS-DYNA Theory Manual, Livermore Software Technology Corporation, Livermore, CA, USA, 2007.

[35] R. Vignjevic, M. Orłowski, T. De Vuyst, and J. C. Campbell, "A parametric study of bird strike on engine blades," International Journal of Impact Engineering, vol. 60, pp. 44-57, 2013.

[36] G. R. Johnson and W. H. Cook, "Fracture characteristics of three metals subjected to various strains, strain rates, temperatures and pressures," Engineering Fracture Mechanics, vol. 21, no. 1, pp. 31-48, 1985.

[37] D. Leseur, Experimental Investigations of Material Models for Ti-6A1-4V and 2024-T3, Lawrence Livermore National Lab., Livermore, CA, USA, UCRL-ID-134691, 1999.

[38] C. Yang, Y. Jiang, W. He, J. Na, Z. Li, and B. Xu, "Adaptive parameter estimation and control design for robot manipulators with finite-time convergence," IEEE Transactions on Industrial Electronics, vol. 65, no. 10, pp. 8112-8123, 2018.

[39] C. Yang, G. Peng, L. Cheng, J. Na, and Z. Li, "Force sensorless admittance control for teleoperation of uncertain robot manipulator using neural networks," IEEE Transactions on Systems, Man, and Cybernetics: Systems, pp. 1-11, 2019.

[40] G. Peng, C. Yang, W. He, and C. L. P. Chen, "Force sensorless admittance control with neural learning for robots with actuator saturation," IEEE Transactions on Industrial Electronics, vol. 67, no. 4, pp. 3138-3148, 2020.
[41] C. Yang, H. Wu, Z. Li, W. He, N. Wang, and C.-Y. Su, "Mind control of a robotic arm with visual fusion technology," IEEE Transactions on Industrial Informatics, vol. 14, no. 9, pp. 3822-3830, 2018.

[42] H. Lin, T. Zhang, Z. Chen, H. Song, and C. Yang, "Adaptive fuzzy Gaussian mixture models for shape approximation in robot grasping," International Journal of Fuzzy Systems, vol. 21, no. 4, pp. 1026-1037, 2019. 